\title{
WILEY-VCH
}

DOI: 10.1002/ ((please add manuscript number))

Article type: Full Paper

\section{Potassium Prussian Blue Nanoparticles: A Low-cost Cathode Material for Potassium- ion Batteries}

Chenglin Zhang, Yang Xu, Min Zhou, Liying Liang, Huishuang Dong, Minghong Wu, Yi Yang, Yong Lei*

C. L. Zhang, H. S. Dong, Dr. M. H. Wu, Y. Yang, Prof. Y. Lei

Institute of Nanochemistry and Nanobiology, School of Environmental and Chemical

Engineering, Shanghai University, Shanghai 200444, P. R. China

E-mail: yong.lei@tu-ilmenau.de

Dr. Y. Xu, Dr. M. Zhou, L. Y. Liang, Prof. Y. Lei

Institute für Physik \& IMN MacroNano (ZIK), Technische Universität Ilmenau, Ilmenau 98693, Germany

Keywords: potassium-ion batteries, Prussian blue, nanoparticles, cathode, full cell

Potassium-ion batteries (KIBs) in organic electrolytes hold great promise as an electrochemical energy storage technology owing to the abundance of potassium, close redox potential to lithium, and similar electrochemistry with lithium system. Although carbon materials have been studied as KIB anodes, investigations on KIB cathodes have been scarcely reported. We for the first time report a comprehensive study on potassium Prussian blue $\mathrm{K}_{0.220} \mathrm{Fe}\left[\mathrm{Fe}(\mathrm{CN})_{6}\right]_{0.805} \cdot 4.01 \mathrm{H}_{2} \mathrm{O}$ nanoparticles as a potential cathode material. The cathode exhibits a high discharge voltage of 3.1 3.4 V, high reversible capacity of $73.2 \mathrm{mAh}$ $\mathrm{g}^{-1}$, and great cyclability at both low and high rates with a very small capacity decay rate of $\sim 0.09 \%$ per cycle. Electrochemical reaction mechanism analysis identifies the carboncoordinated $\mathrm{Fe} \mathrm{e}^{\mathrm{III}} / \mathrm{Fe}^{\mathrm{II}}$ couple as redox-active site and proves structural stability of the cathode during charge/discharge. Furthermore, for the first time, we present a KIB full-cell by coupling the nanoparticles with commercial carbon materials. The full-cell delivers a capacity of $68.5 \mathrm{mAh} \mathrm{g}^{-1}$ at $100 \mathrm{~mA} \mathrm{~g}^{-1}$ and retains $93.4 \%$ of the capacity after 50 cycles. Considering the low cost and material sustainability as well as the great electrochemical performances, this work may pave the way towards more studies on KIB cathodes and trigger future attention on rechargeable KIBs. 


\section{WILEY-VCH}

\section{Introduction}

The rapid increase in powering portable electronic devices and vehicles has caused a mass production of Li-ion batteries (LIBs). ${ }^{[1]}$ The demand of LIBs is still growing because power storage units for large-scale stationary applications need to supplement irregular power generation and consumption patterns so that intermittent renewable energies can be efficiently stored and utilized. ${ }^{[2]}$ However, the rising costs and availability of global lithium resources have raised concerns about the heavy reliance on LIBs because most easily accessible lithium reserves are in either remote or politically sensitive areas. ${ }^{[3]}$ The fact that stationary applications are indispensable for the deployment of renewable energies and low cost upon scaling up is one of the basic prerequisites calls for alternative Earth-abundant metal-ion batteries with similar electrochemical principles. The abundance of sodium in Earth's crust is three orders higher than that of lithium, ${ }^{[4]}$ making Na-ion batteries (NIBs) a potential candidate for stationary applications. The redox potential of $\mathrm{Na} / \mathrm{Na}^{+}$is $-2.71 \mathrm{~V}$ (vs. SHE), which is $0.3 \mathrm{~V}$ more positive than that of $\mathrm{Li}$, so there is an energy penalty to pay. NIBs have received considerable attention recently, demonstrating encouraging capacity and cycle life as well as rate capability. ${ }^{[5]}$ In fact, potassium has a comparably high natural abundance as sodium ${ }^{[4 \mathrm{c}]}$ and the redox potential of $\mathrm{K} / \mathrm{K}^{+}(-2.92 \mathrm{~V}$ vs. SHE) is even lower than that of $\mathrm{Na} / \mathrm{Na}^{+}$, indicating a comparably low cost but even higher energy density of K-ion batteries (KIBs). Unfortunately, very small progress has been made on the side of KIBs so far.

KIBs came into focus very recently owing to the successful implantation of carbonaceous materials (graphitic and non-graphitic ${ }^{[6]}$ ) as KIB anodes in nonaqueous electrolytes. Electrochemical insertion of K-ions into graphitic carbons was reported as a reversible three-step phase transformation process. ${ }^{[6 a]}$ Both graphite ${ }^{[6 b]}$ and reduced graphene oxide ${ }^{[6 a]}$ exhibited significantly larger capacity (typically over $200 \mathrm{mAh} \mathrm{g}^{-1}$ ) 


\section{WILEY-VCH}

in KIBs than in NIBs. However, they suffer fast capacity fading and moderate capability. Non-graphitic carbons, such as hard carbon microspheres, ${ }^{[6 \mathrm{c}]}$ were found to address this issue and exhibited improved cycle life and rate capability. Additionally, metallic Sb has been used as KIB anode as well. ${ }^{[7]}$ Despite the progress made on the anode side, study on the cathode side hasn't followed to the same extent, presumably due to the larger ionic radii of $\mathrm{K}$-ion $\left(\mathrm{Li}^{+}<\mathrm{Na}^{+}<\mathrm{K}^{+}, 0.76<1.02<1.38 \AA\right.$ ) that causes significant restrictions for use with intercalation type electrodes. Investigations of cathode materials of KIBs in nonaqueous electrolytes have been scarcely reported. ${ }^{[8]}$ Lack of such investigations thus hinders the advancement of KIB full-cells.

Prussian blue (PB) and its analogues (PBAs) have been explored for many different applications for decades because of their ease of synthesis and intriguing electrochemical and magnetic properties. ${ }^{[9]}$ The general chemical formula of PBAs is $\mathrm{A}_{\mathrm{x}} \mathrm{M}\left[\mathrm{M}^{\prime}(\mathrm{CN})_{6}\right]_{1-\mathrm{y}} \mathrm{y}_{\mathrm{y}} \cdot \mathrm{nH}_{2} \mathrm{O}$ $(0<\mathrm{x}<2, \mathrm{y}<1)$, where A represents mobile cations, $\mathrm{M}$ represents nitrogen-coordinated transition metal ions, $M^{\prime}$ represents carbon-coordinated transition metal ions (the formula represents $\mathrm{PB}$ when $\left.\mathrm{M}=\mathrm{M}^{\prime}=\mathrm{Fe}\right)$, and $\square$ represents $\left[\mathrm{M}^{\prime}(\mathrm{CN})_{6}\right]$ vacancy. PBAs typically possess a face-centered cubic $(f c c)$ crystal structure that has a three dimensional (3D) network in which transition metal ions are linked together through cyanide $(\mathrm{CN})$ ligands (Figure 1). Each unit cell contains eight subunit cells (indicated by the red cell edges in Figure 1a) and therefore contains eight interstitial sites that can accommodate not only neutral molecules but ions charge-balanced by the transition ions. ${ }^{[10]}$ Interstitial water is commonly found within the 3D network of the PBAs and have two structurally distinguishable kinds, namely zeolitic water (1) and coordinating water (2). The former occupies the octahedral center of the subunits and the latter chemically coordinates with the $M$ ions because of the $\left[M^{\prime}(C N)_{6}\right]$ vacancy locating at the center of the unit cell (Figure 1b). ${ }^{[11]}$ The 3D network, as the most distinguish structural feature of the PBAs, provides open channels along <100> direction and interstitial sites with the diameters of $3.2 \AA$ and $4.6 \AA$, respectively, in the case of PB. ${ }^{[12]}$ Such 


\section{WILEY-VCH}

open scaffolding leaves large cavities within, and tunnels running in three directions throughout the roomy lattice that enables rapid solid-state diffusion of a wide variety of intercalated ions, upon which the electrochemical properties of the PBAs can be attributed to the redox behavior of the transition metal ions. In fact, PBAs were investigated as hosts for alkali ions in both nonaqueous ${ }^{[11 \mathrm{a}]}$ and aqueous electrolytes ${ }^{[13]}$ years ago and recently regained attention from the scientific community owing to their success in NIBs. PBAs containing different transition metal ions $\left(\mathrm{Fe},{ }^{[14]} \mathrm{Mn},{ }^{[15]} \mathrm{Co},{ }^{[16]}\right.$ and $\left.\mathrm{Ni}^{[16]}\right)$ have been demonstrated as NIB cathode materials in nonaqueous electrolytes. In aqueous electrolytes, it has been reported that PBAs exhibited favorable electrochemical activity upon reversible insertion and extraction of $\mathrm{Na}^{+}$and $\mathrm{K}^{+} \cdot{ }^{[9 b, 17]}$ To the best of our knowledge, very little concern has been shown for PB and PBAs as KIB electrode materials in nonaqueous electrolytes. An early work primarily showed the possibility of PB film as a KIB cathode with a mass loading only around $80 \mu \mathrm{g},{ }^{[18]}$ but it received little attention presumably because of the extremely low testing rate $\left(\sim 8.7 \mathrm{~mA} \mathrm{~g}^{-1}\right)$, an insufficiency to demonstrate the rate performance and, more importantly, a lack of illustrating its application in an actual KIB full-cell.

In this work, we report a comprehensive study on potassium Prussian blue nanoparticles (KPBNPs) as a low-cost KIB cathode in nonaqueous electrolytes. The KPBNPs cathode exhibits a high discharge voltage of 3.1 3.4 V and great cycle life at both low $\left(73.2 \mathrm{mAh} \mathrm{g}^{-1}\right.$ at $\left.50 \mathrm{~mA} \mathrm{~g}^{-1}\right)$ and high rates $\left(36.0 \mathrm{mAh} \mathrm{g}^{-1}\right.$ at $\left.400 \mathrm{~mA} \mathrm{~g}^{-1}\right)$, possessing a very small capacity decay rate of $\sim 0.09 \%$ per cycle. The electrochemical reaction mechanism study reveals that the redox-active site of the KPBNPs is the carbon-coordinated $\mathrm{Fe}^{\mathrm{III}} / \mathrm{Fe}^{\mathrm{II}}$ couple. Furthermore, for the first time, we present an operational KIB full-cell by coupling the KPBNPs with the commercially available carbon material Super P. The full-cell delivers a capacity of $68.5 \mathrm{mAh}$ $\mathrm{g}^{-1}$ at $100 \mathrm{~mA} \mathrm{~g}^{-1}$ and retains $93.4 \%$ of the capacity after 50 cycles. Considering the low cost and material sustainability as well as the great electrochemical performances of the KPBNPs, our work highlights the promise of PB and PBAs in the field of KIBs. 


\section{WILEY-VCH}

\section{Results and Discussion}

\subsection{Morphology and Structural Analysis}

KPBNPs were synthesized by a facile precipitation method in an aqueous solution containing $\mathrm{K}_{4} \mathrm{Fe}(\mathrm{CN})_{6}$ and $\mathrm{FeCl}_{3}$, in which complicated operation or tedious process is not required. The experimental details can be found in the Supporting Information. To obtain the chemical composition, the inductively couple plasma atomic emission spectroscopy (ICP-AES) method and elemental analysis were used to determine the mass ratios of the heavy elements, i.e. $\mathrm{K}$ and $\mathrm{Fe}$, and the light elements, i.e. $\mathrm{C}, \mathrm{N}$ and $\mathrm{H}$, respectively (Table S1). Assuming a $\mathrm{Fe}(\mathrm{CN})_{6}$ unit, the chemical composition of the as-prepared KPBNPs is determined to be $\mathrm{K}_{0.220} \mathrm{Fe}\left[\mathrm{Fe}(\mathrm{CN})_{6}\right]_{0.805}{ }^{\circ} \square_{0.195^{*}} 4.01 \mathrm{H}_{2} \mathrm{O}$, which suggests the presence of a considerable amount of $\left[\mathrm{Fe}(\mathrm{CN})_{6}\right]^{4-}$ vacancy. Thermogravimetric (TG) analysis shows two weight-loss events (Figure S1): the first step occurring below $200^{\circ} \mathrm{C}$ corresponds to the loss of the physically absorbed and zeolitic water, and the second step occurring above $200^{\circ} \mathrm{C}$ can be assigned to the elimination of the coordinated water and the decomposition of the PB framework. ${ }^{[11 b, 19]}$ The weight loss over the first step corresponds to 3.79 water molecules per formula and it is difficult to determine the amount of the coordinated water from the second step because of the overlap between the two occurring processes. However, by abstracting the amount of the water determined in the first step from the total amount of the water determined in the chemical composition, it is reasonable to estimate the amount of the coordinated water to be 0.22 , which is very close to the value of the $\left[\mathrm{Fe}(\mathrm{CN})_{6}\right]^{4-}$ vacancy per formula in the chemical composition within the experimental error.

Figure 2a shows the X-ray diffraction (XRD) pattern of the as-prepared KPBNPs and the standard pattern of $\mathrm{Fe}_{4}\left[\mathrm{Fe}(\mathrm{CN})_{6}\right]_{3}$ (JCPDS No. 52-1907). Although there is a lack of accurate information on $\mathrm{K}_{0.220} \mathrm{Fe}\left[\mathrm{Fe}(\mathrm{CN})_{6}\right]_{0.805} \square^{\circ} 0.195 \cdot 4.01 \mathrm{H}_{2} \mathrm{O} \quad$ compound in the existing crystallographic database, it can be seen that the two patterns are almost identical to each other. By the analogy between the obtained compound and the similar $\mathrm{PB}^{[14 \mathrm{~b}]}$ and $\mathrm{MFe}-\mathrm{PB}(\mathrm{M}$ 


\section{WILEY-VCH}

$=\mathrm{Mn}, \mathrm{Co}$, and Ni) compounds, ${ }^{[16]}$ we can speculate that our sample contains the structure of $\mathrm{PB}$, in which both the 3D cyanide-bridged framework and the 3D porous channel exist with $\mathrm{K}^{+}$placing in the center of the subunits, thus supporting our calculated chemical composition. The broadened diffraction lines reflect the small size of the particles. By using the Scherrer's formula on the widths of the XRD peaks, an average grain size is estimated to be $8.2 \mathrm{~nm}$, which is in agreement of the HRTEM results (Figure 2f). X-ray photoelectron spectroscopy (XPS) provides further confirmation of the chemical composition. The survey spectrum (Figure 2b) shows the presence of only $\mathrm{K}, \mathrm{Fe}, \mathrm{C}, \mathrm{N}$, and $\mathrm{O}$. In the Fe $2 \mathrm{p}$ spectrum (Figure 2c), the binding energies of $\mathrm{Fe} 2 \mathrm{p} 3 / 2$ and Fe2p1/2 are observed at 711.8 and $724.8 \mathrm{eV}$, respectively, which originates from the presence of $\mathrm{Fe}^{3+}$. The peaks located at 707.7 and $720.7 \mathrm{eV}$ can be assigned to $\mathrm{Fe}^{2+}$ in the $\left[\mathrm{Fe}(\mathrm{CN})_{6}\right]^{4-}$ unit, being consistent with literature reported elsewhere. ${ }^{[20]}$ Both scanning electron spectroscopy (SEM, Figure 2d) and transmission electron spectroscopy (TEM) images (Figure 2e) reveal that the sample is composed of the well-dispersed nanoparticles with the uniform size of $20 \sim 30 \mathrm{~nm}$. Undoubtedly, such a nanosized morphology is structurally favorable for electron and $\mathrm{K}^{+}$ transportation during the electrochemical redox reactions. The energy dispersive spectroscopy (EDS) measurement once again demonstrates the elemental purity of the KPBNPs (inset in Figure 2d). Furthermore, as shown in the high-resolution TEM (HRTEM) image (Figure 2f), clear lattice fringes and a grain size of $\sim 8 \mathrm{~nm}$ can be seen, where the interplanar specings of $\mathrm{d}$ $=0.50,0.36$ and $0.24 \mathrm{~nm}$ correspond to the diffraction planes of (200), (220) and (420), respectively. Therefore, the crystalline nature of the nanoparticles can be confirmed.

\subsection{KIB Half-cell Performance}

The K storage behavior of the KPBNPs is firstly tested in half-cell configuration against metallic potassium, with working voltage window of $2.0 \sim 4.0 \mathrm{~V}\left(\mathrm{vs} . \mathrm{K} / \mathrm{K}^{+}\right)$. Figure 3a shows the cyclic voltammetry $(\mathrm{CV})$ curves of KPB cathode at a scan rate of $0.1 \mathrm{mV} \mathrm{s}^{-1}$. The main 


\section{WILEY-VCH}

feature of the cathode is a pair of symmetric and reproducible redox peaks. During the first scan, the anodic and cathodic peaks locate at 3.53 and $3.18 \mathrm{~V}$, respectively. In the subsequent scans, the anodic peak shifts to $3.64 \mathrm{~V}$ while the cathodic peak remains around $3.16 \mathrm{~V}$. It is worth nothing that the shapes and areas of the peaks remain almost unchanged during the successive scans, suggesting a very reversible redox reaction occurring at high potential interval, which can be assigned to the $\mathrm{C}-\mathrm{Fe}^{\mathrm{III}} / \mathrm{Fe}^{\mathrm{II}}$ couple through a reversible $\mathrm{K}^{+}$ intercalation/deintercalation mechanism (will be discussed later). The galvanostatic charge/discharge profiles of the KPB cathode tested at current density of $50 \mathrm{~mA} \mathrm{~g}^{-1}$ are shown in Figure 3b and 3c. The electrode displayed an open-circuit voltage (OCV) of $3.0 \mathrm{~V}$ (Figure 3b). Two semi-plateaus can be found in Figure 3c: one locates at 3.4 3.8 V during charging and the other locates at 3.1 3.4 V during discharging, which is in a close correspondence with the $\mathrm{CV}$ results. The first charge and discharge capacities are 174.1 and $76.7 \mathrm{mAh} \mathrm{g}^{-1}$, respectively, resulting in the cycle1 Coulombic Efficiency (CE) of 44.0\%. As shown in Figure 3d, from cycle 2 to cycle 50, the charge capacity gradually decreases presumably due to the decrease of the interstitial water, while the discharge capacity remains stable, giving rise to the gradually increased $\mathrm{CE}$ during cycling. The initially low and gradually increased $\mathrm{CE}$ are associated with the relatively large amount of the interstitial water. ${ }^{[21]}$ It is doubtful that the interstitial water can be totally removed from the lattice. Decomposition of the residual water during charge process would cause a low CE. With subsequent cycles, the amount of residual water would decrease and thus the CE increases. ${ }^{[16]}$ Therefore, as will be presented later, prior to assemble the full-cell, the KPB cathode was pre-activated by being galvanostatically cycled in a half-cell configuration. In this case, the initially low $\mathrm{CE}$ in a half-cell did not affect the full-cell energy. Nevertheless, it is worth pointing out that the charge and discharge plateaus remain almost unchanged, indicating a low polarization at the present rate and suggesting a high reversibility of the $\mathrm{K}^{+}$insertion into and extraction from the 3D network as first indicated in the CV results. The capacities of 74.5 and $73.2 \mathrm{mAh} \mathrm{g}^{-1}$ are observed at cycle 2 and cycle 50 


\section{WILEY-VCH}

(Figure 3c), respectively, corresponding to a stably reversible storage of $\sim 0.84$ mol $\mathrm{K}^{+}$per formula. The capacities are even higher than that of the PBAs in aqueous electrolytes at a similar rate. ${ }^{[9 b, 17 a]}$ The decay rates are calculated to be $0.036 \%$ per cycle relative to cycle 2 and $0.091 \%$ per cycle relative to cycle 1 . Such low decay rates indicate minimum structural change during cycling, which can be evidenced by the post-cycling characterizations. As shown in Figure S2a, the XRD pattern tested after 50 cycles displays the original diffraction peaks as in Figure 2a, and the decreased intensity of (200) peak is likely due to the repeated insertion/extraction of K-ions along $<100>$ direction. The clear lattice fringes in Figure S2c and S2d unambiguously indicate the stability of the microscopic crystal structures during charge/discharge. As a result, the macroscopic morphology of the nanosized particles is preserved as shown in Figure S2b.

The rate performance of the KPB cathode is shown in Figure 4a at the currant densities ranging from 50 to $400 \mathrm{mAh} \mathrm{g}^{-1}$. The cathode delivers a discharge capacity of $65.0 \mathrm{mAh} \mathrm{g}^{-1}$ at $100 \mathrm{~mA} \mathrm{~g}^{-1}$, nearly $90 \%$ of the capacity at $50 \mathrm{~mA} \mathrm{~g}^{-1}$. When the rate increases to 200,300 and $400 \mathrm{~mA} \mathrm{~g}^{-1}$, the cathode provides the capacities of $56.1,46.1$, and $36.0 \mathrm{mAh} \mathrm{g}^{-1}$, respectively. After cycled at high rates, a capacity of $72.0 \mathrm{mAh} \mathrm{g}^{-1}$ is observed when the rate is reduced back to $50 \mathrm{~mA} \mathrm{~g}^{-1}$, indicating a full recovery of the low rate capacity. The charge/discharge profiles at different rate are shown in Figure S3. Strikingly, the KPB cathode exhibited a great cycling stability at higher rates. As shown in Figure 4b, the capacities of 52.4 and 44.7 $\mathrm{mAh} \mathrm{g}^{-1}$ are retained over 150 cycles at the rate of 200 and $300 \mathrm{~mA} \mathrm{~g}^{-1}$, respectively. In both cases, the decay rate is calculated to be $\sim 0.09 \%$ per cycle relative to cycle 1 , which is similar to the decay rate at low rate $\left(50 \mathrm{~mA} \mathrm{~g}^{-1}\right)$, demonstrating the great cyclability at different rates. As indicated earlier, we attribute the great rate performance of the KPBNPs to their macroscopically nanosized morphology and microsocpically 3D framework with open channels. Combined, these two features minimize $\mathrm{K}$ diffusional resistance both within the liquid electrolyte and in solid-state. To the best of our knowledge, the presented cycle life at 


\section{WILEY-VCH}

low $\left(50 \mathrm{~mA} \mathrm{~g}^{-1}\right)$ and higher rates as well as the rate capability are the first reported results of the PB- and PBA-based KIB cathodes in nonaqueous electrolytes. Therefore, considering the low cost and material sustainability of KPB, its high reversible capacity, excellent cycling stability, and good rate capability make it a good candidate for electrochemical potassium storage applications.

\subsection{Electrochemical Mechanism Study}

To confirm the great cyclability and redox-active site of the KPBNPs, a series of ex-situ measurements were carried out to investigate the electrochemical reaction mechanism. Figure 5c displays the XRD patterns collected at different charge/discharge states as denoted in Figure 5a. As seen, all the patterns remain unchanged comparing with the pattern obtained before the cycling, indicating that the $\mathrm{K}^{+}$insertion/extraction proceeds via a solid-solution process, i.e. an intercalation mechanism is responsible for the electrochemical $\mathrm{K}$ storage in the KPB cathode. Close observation reveals that the lattice parameter decreases during charging ( $\mathrm{K}^{+}$extraction, a-c), as illustrated by a shift in the position of the (200) diffraction peak to smaller angles (Figure 5d). During discharging (d-g), the diffraction peak shifts back to the larger angles, suggesting the increase of the lattice parameter because of the $\mathrm{K}^{+}$insertion. The isotropic lattice reduction reaches $1.9 \%$ (10.280 to $10.082 \AA$ ) during $\mathrm{K}^{+}$extraction and the lattice expansion reaches $1.6 \%$ (10.082 to $10.246 \AA$ ) during $\mathrm{K}^{+}$insertion (Figure 5e). The volume change thus can be estimated to be up to $6.9 \%$, which correlates with the great cycle life as shown in Figure 3d. PB may be oxidized to Prussian yellow, containing all Fe(III) in $\mathrm{Fe}^{\mathrm{III}}\left[\mathrm{Fe}^{\mathrm{III}}(\mathrm{CN})_{6}\right]$, or reduced to Prussian white, containing all $\mathrm{Fe}(\mathrm{II})$ in $\mathrm{Fe}^{\mathrm{II}}\left[\mathrm{Fe}^{\mathrm{II}}(\mathrm{CN})_{6}\right]^{2-}$, upon a flow of cations in or out of the lattice to balance the change in overall electric charge. ${ }^{[21]}$ When the amount of the intercalated cations is higher than averagely 1 cation per formula, a phase transition from cubic to rhombohedral structure has been observed in both $\mathrm{Li}^{[22]}$ and $\mathrm{Na}$ system. ${ }^{[14 b, 23]}$ Analogically, the unchanged cubic structure during cycle hints that the redox- 


\section{WILEY-VCH}

active site can be assigned to the $\mathrm{C}-\mathrm{Fe}^{\mathrm{III}} / \mathrm{Fe}^{\mathrm{II}}$ couple in our case. Therefore, we employed $e x$ situ Raman spectroscopy to verify our speculation. As shown in Figure 5b, all the spectra collected at different charge and discharge states display two major peaks locating between $2070 \sim 2160 \mathrm{~cm}^{-1}$, both of which are attributed to the cyanide stretching vibration mode, $v(\mathrm{CN})$, and sensitive to the surrounding chemical environment. Cyanide coordinated to $\mathrm{Fe}^{\mathrm{II}}$ exhibits peaks at lower wavenumber than that coordinated to $\mathrm{Fe}^{\mathrm{III}}$. [24] Thus the peak at $2080 \mathrm{~cm}^{-1}$ can be assigned to the C-coordinated high-spin $\mathrm{Fe}^{\mathrm{II}}$ (denoted as $\mathrm{Fe}^{\mathrm{II}}$-peak) while the one at $\sim 2013$ $\mathrm{cm}^{-1}$ can be assigned to the $\mathrm{N}$-coordinated low-spin $\mathrm{Fe}^{\mathrm{III}}$ (denoted as $\mathrm{Fe}^{\mathrm{III}}$-peak). ${ }^{[15 \mathrm{~b}]}$ During charging, the relative intensity of $\mathrm{Fe}^{\mathrm{II}}$-peak to $\mathrm{Fe}^{\mathrm{III}}$-peak decreases with $\mathrm{K}^{+}$extracting from the lattice, suggesting that the redox pair of $\left[\mathrm{Fe}^{\mathrm{II}}(\mathrm{CN})_{6}\right]^{4-} /\left[\mathrm{Fe}^{\mathrm{III}}(\mathrm{CN})_{6}\right]^{3-}$ is dominating the electrochemical $\mathrm{K}^{+}$storage. Then change proceeds in an opposite manner during discharging, further confirming the responsibility of the C-coordinated Fe for storing charge. Furthermore, it is obvious that $v(\mathrm{CN})$ shifts gradually towards higher (lower) wavenumber positions during charging (discharging), revealing an increase (decrease) in the average valence state of $\mathrm{Fe}$, which is consistent with the $\mathrm{K}^{+}$extraction (insertion). In addition, the same trend can be found in the $e x$-situ XPS measurement (Figure S4) where the intensities of the peaks related to $\mathrm{Fe}^{3+}$ $2 p$ increase during charging and decrease during discharging. Therefore, combining the results of ex-situ XRD, Raman and XPS measurement, it can be concluded that, in our case, the $\mathrm{C}-\mathrm{Fe}^{\mathrm{III}} / \mathrm{Fe}^{\mathrm{II}}$ couple is identified as the redox-active site and thus electrochemically responsible for $\mathrm{K}$ storage.

\subsection{KIB Full-cell Performance}

To display the application of the KPBNPs in full-cell configuration, for the first time, we report an operational KIB full-cell. The cell was paired using the KPBNPs as cathode and commercial carbon black Super $\mathrm{P}$ as anode, the rationale behind which is that both materials are cost-effective and materially sustainable and, as proven in the case of LIBs, the maturity 


\section{WILEY-VCH}

of the commercialization has always relied on carbon-based anodes. The structural and electrochemical characterizations of Super P in half-cell configuration are provided in Figure S5. As aforementioned, from the practical viewpoint of battery application, it is more desired to use a K-rich cathode to couple with a K-deficient anode in order to assemble a full-cell, which requires potassium compensation by pre-discharge with metallic potassium. ${ }^{[5 c]}$ Figure 6a shows the charge/discharge profiles of the full cell at the current density of $100 \mathrm{~mA} \mathrm{~g}^{-1}$ tested at $1.0 \sim 3.8 \mathrm{~V}$, where semi-plateaus can be found during charging or discharging. According to the voltage range of Super P (charge: 0.6 1.1 V; discharge: 0.2 0.6 V, Figure S5b) and KPBNPs (Figure 3c), it is reasonable to deduce that the full cell operates at the range of 2.6 3.2 V (charge) and 2.2 2.8 V (discharge), as indeed shown in Figure 6a. The cell is able to light a red (working voltage: 1.9 2.2 V) and white LED (working voltage: 2.9 3.3 V) after being fully charged (Figure $6 \mathbf{b}$ and $\mathbf{6 c}$ ). A discharge capacity of around 65 $\mathrm{mAh} \mathrm{g}^{-1}$ is delivered and in accordance with the capacity in the step-wise rate testing at the same current density (Figure 4a), proving the suitability of the cathode-to-anode mass ratio in the cathode-limited configuration. The cycling performance is displayed in Figure 6d, revealing that the full-cell is stable and retains $64.0 \mathrm{mAh} \mathrm{g}^{-1}$ after 50 cycles, which is $93.4 \%$ of the capacity of cycle2. It is worth noting that the initial CE $(49.8 \%)$ of the full-cell is relatively low (Figure 6d and S6) and it increases gradually during cycling, which is similar to the half-cell and can be attributed to the relatively low CE of Super P during early stage of the cycling as shown in half-cell (Figure S5c), together with the interstitial water in the cathode. Super $\mathrm{P}$ was used as received without any further optimization, thus it can be expected that the full-cell performance could be improved after optimizing the anode carbon (e.g. porosity and nanoarchitectures). Nevertheless, our report on the first operational KIB full-cell undoubtedly demonstrates the promise of the KPBNPs and indicates the potential of other PBAs in KIBs. 


\section{WILEY-VCH}

\section{Conclusion}

In summary, KPBNPs were synthesized by a facile precipitation method and evaluated as cathode materials for KIBs. The cathode exhibited high discharge voltage and great cycle life, delivering the capacities of 73.2 and $36.0 \mathrm{mAh} \mathrm{g} \mathrm{g}^{-1}$ at the rates of 50 and $400 \mathrm{~mA} \mathrm{~g} \mathrm{~g}^{-1}$, respectively, with a very small capacity decay rate of $\sim 0.09 \%$ per cycle. Electrochemical mechanism study revealed that the $\mathrm{C}$-coordinated $\mathrm{Fe}$ is the active-redox site and thus electrochemically responsible for K storage. The use of KPBNPs might give new insight into the design of cathode materials for room-temperature KIBs. Moreover, the first successful realization of the KIB full-cell indicates that the environmental friendliness and low cost of the cathodic material enable PB and PBAs to be used for large-scale electrochemical energy storage applications. We hope that our work could potentially trigger more future study on cathode materials of KIBs and further stimulate attentions on potassium storage applications.

\section{Experimental Section}

Materials Synthesis: KPBNPs were synthesized by a facile precipitation method in an aqueous solution. In a typical synthesis, $\mathrm{K}_{4} \mathrm{Fe}(\mathrm{CN})_{6}(1 \mathrm{mmol})$ was dissolved in deionized water $(160 \mathrm{ml})$ to form solution $\mathrm{A}$, and $\mathrm{FeCl}_{3}(2 \mathrm{mmol})$ was dissolved in deionized water (40 ml) to form solution B. Solution B was dropwise added into solution A under stirring and precipitation formed immediately. The mixture solution was stirred for $2 \mathrm{~h}$ and aged for another 24 hours. The obtained dark blue precipitates were collected by centrifugation, washed by water and ethanol, and dried at $80^{\circ} \mathrm{C}$ in a vacuum oven for $24 \mathrm{~h}$.

Materials Characterizations: X-ray diffraction (XRD) analysis was performed on a $18 \mathrm{KW}$ D/MAX2500V PC diffractometer using $\mathrm{Cu} \mathrm{K \alpha}(\lambda=1.54 \AA)$ radiation at a scanning rate of $2^{\circ}$ $\min ^{-1}$. Scanning electron microscopy (SEM) and energy dispersive spectroscopy (EDS) analysis were conducted using a Hitachi S4800 field emission scanning microscopy. Transmission electron microscopy (TEM) analysis was performed on a JEOL 2100F 


\section{WILEY-VCH}

transmission electron microscope. X-ray photoelectron spectra (XPS) were acquired on an ESCALAB 250Xi with $\mathrm{Mg} \mathrm{K \alpha}(\mathrm{hv}=1253.6 \mathrm{eV})$ as the excitation source. The binding energies obtained in the XPS spectra analysis were corrected for specimen charging by referencing $\mathrm{C} 1 \mathrm{~s}$ to $284.8 \mathrm{eV}$. Raman spectra were recorded at room temperature with an inVia Raman microscope. ICP-AES measurement was performed on a PerkinElmer Optima 7300DV ICP-AES Spectrometers. Element analysis was conducted using an Elementar vario MICRO cube. Thermogravimetric (TG) analysis was conducted using a NETZSCH STA 409 PG/PC instrument.

Electrochemical Measurements: Electrodes were fabricated by mixing KPBNPs, Super P and poly(vinylidenedifluoride) (PVDF) at a weight ratio of 60:30:10, then coated uniformly (doctor-blade) on an aluminum foil with a mass loading of $\sim 1.5 \mathrm{mg} \mathrm{cm}^{-2}$. The electrodes were dried at $70^{\circ} \mathrm{C}$ under vacuum for $12 \mathrm{~h}$. Electrochemical tests were carried out using a coin-cell configuration, CR2032, which were assembled in a $\mathrm{N}_{2}$-filled glovebox with oxygen and moisture concentrations kept below $0.1 \mathrm{ppm}$. K foil used as counter electrode was separated from working electrode using a glass microfiber filter (Whatman, Grade GF/B). The electrolyte was $0.8 \mathrm{M} \mathrm{KPF}_{6}$ in an ethylene carbonate (EC)-diethyl carbonate (DEC) solution $(1: 1, \mathrm{v}: \mathrm{v})$. Cyclic voltammetry $\left(\mathrm{CV}, 0.1 \mathrm{mV} \mathrm{s}^{-1}, 2.0-4.0 \mathrm{~V}\left(\mathrm{vs} . \mathrm{K} / \mathrm{K}^{+}\right)\right)$was performed on a VSP electrochemical workstation (Bio-Logic, France). Galvanostatic charge/discharge was performed in a voltage range of 2.0-4.0 V on a Land CT 2001A battery testing system (Land, China) at room temperature.

The full cell was assembled using KPB as cathode and commercial Super P as anode using the same separator and electrolyte. The anode was fabricated in the same way as cathode. To ensure a suitable cathode-to-anode capacity ratio for a proper cell balance, cathode-limited configuration was chosen with a cathode-to-anode mass loading ratio of $\sim 1.1$. Galvanostatic charge/discharge was performed in a voltage range of 1.0-3.8 V. 


\section{WILEY-VCH}

\section{Acknowledgements}

This work is financially supported by the European Research Council (ThreeDsurface, 240144), BMBF (ZIK-3DNanoDevice, 03Z1MN11), BMBF (Meta-ZIK-BioLithoMorphie, 03Z1M512), German Research Foundation (DFG: LE 2249_4-1), National Natural Science Foundation of China (21577086), and Shanghai Thousand Talent Plan. C. L. Zhang and Dr. Y. $\mathrm{Xu}$ contributed equally to this work.

Received: ((will be filled in by the editorial staff))

Revised: ((will be filled in by the editorial staff)) Published online: ((will be filled in by the editorial staff))

[1] a) B. Dunn, H. Kamath, J.-M. Tarascon, Science 2011, 334, 928; b) T. Nagaura, K. Tozawa, JEC Press 1990, 9, 209.

[2] G. Jeong, Y.-U. Kim, H. Kim, Y.-J. Kim, H.-J. Sohn, Energy Environ. Sci. 2011, 4, 1986.

[3] a) S. Fletcher, Bottled Lightning: Superbatteries, electric cars, and the new lithium economy, Macmillan, 2011; b) F. Risacher, B. Fritz, Aquatic Geochemistry 2009, 15, 123; c) A. Yaksic, J. E. Tilton, Resources Policy 2009, 34, 185.

[4] a) R. Berthelot, D. Carlier, C. Delmas, Nat. Mater. 2011, 10, 74; b) N. Yabuuchi, M. Kajiyama, J. Iwatate, H. Nishikawa, S. Hitomi, R. Okuyama, R. Usui, Y. Yamada, S. Komaba, Nat. Mater. 2012, 11, 512; c) G. B. Haxel, J. B. Hedrick, G. J. Orris, P. H. Stauffer, J. W. Hendley II, 2002.

[5] a) N. Yabuuchi, K. Kubota, M. Dahbi, S. Komaba, Chem. Rev. 2014, 114, 11636; b) Y. Xu, M. Zhou, Y. Lei, Adv. Energy Mater. 2016, 1502514; c) D. Kundu, E. Talaie, V. Duffort, L. F. Nazar, Angew. Chem. Int. Ed. 2015, 54, 3431; d) L. Liang, Y. Xu, C. Wang, L. Wen, Y. Fang, Y. Mi, M. Zhou, H. Zhao, Y. Lei, Energy Environ. Sci. 2015, 8, 2954; e) M. D. Slater, D. Kim, E. Lee, C. S. Johnson, Adv. Funct. Mater. 2013, 23, 947; f) S. W. Kim, D. H. Seo, X. Ma, G. Ceder, K. Kang, Adv. Energy Mater. 2012, 2, 710; g) Y. Xu, M. Zhou, L. Wen, C. Wang, H. Zhao, Y. Mi, L. Liang, Q. Fu, M. Wu, Y. Lei, Chem. Mater. 2015, 27, 4274; h) M. Zhou, Y. Xu, J. Xiang, C. Wang, L. Liang, L. Wen, Y. Fang, Y. Mi, Y. Lei, Adv. Energy 


\section{WILEY-VCH}

Mater. 2016, DOI: 10.1002/aenm.201600468; i) C. Wang, Y. Xu, Y. Fang, M. Zhou, L. Liang, S. Singh, H. Zhao, A. Schober, Y. Lei, J. Am. Chem. Soc. 2015, 137, 3124.

[6] a) W. Luo, J. Wan, B. Ozdemir, W. Bao, Y. Chen, J. Dai, H. Lin, Y. Xu, F. Gu, V. Barone, Nano Lett. 2015, 15, 7671; b) Z. Jian, W. Luo, X. Ji, J. Am. Chem. Soc. 2015, 137, 11566; c) Z. Jian, Z. Xing, C. Bommier, Z. Li, X. Ji, Adv. Energy Mater. 2016, 6, 1501874; d) Y. Liu, F. Fan, J. Wang, Y. Liu, H. Chen, K. L. Jungjohann, Y. Xu, Y. Zhu, D. Bigio, T. Zhu, Nano Lett. 2014, 14, 3445.

[7] W. D. McCulloch, X. Ren, M. Yu, Z. Huang, Y. Wu, ACS Appl. Mater. Interfaces 2015, 7, 26158.

[8] a) N. Recham, G. Rousse, M. T. Sougrati, J.-N. Chotard, C. Frayret, S. Mariyappan, B. C. Melot, J.-C. Jumas, J.-M. Tarascon, Chem. Mater. 2012, 24, 4363; b) V. Mathew, S. Kim, J. Kang, J. Gim, J. Song, J. P. Baboo, W. Park, D. Ahn, J. Han, L. Gu, Y. Wang, Y.-S. Hu, Y.-K. Sun, J. Kim, NPG Asia Mater. 2014, 6, e138.

[9] a) C. D. Wessells, R. A. Huggins, Y. Cui, Nat. Commun. 2011, 2, 550; b) C. D.

Wessells, M. T. McDowell, S. V. Peddada, M. Pasta, R. A. Huggins, Y. Cui, ACS Nano 2012, 6, 1688; c) S. Ferlay, T. Mallah, R. Ouahes, P. Veillet, M. Verdaguer, Nature 1995, 378, 701;

d) O. Sato, T. Iyoda, A. Fujishima, K. Hashimoto, Science 1996, 272, 704.

[10] F. Scholz, A. Dostal, Angew. Chem. Int. Ed. 1996, 34, 2685.

[11] a) N. Imanishi, T. Morikawa, J. Kondo, Y. Takeda, O. Yamamoto, N. Kinugasa, T. Yamagishi, J. Power Sources 1999, 79, 215; b) J. Song, L. Wang, Y. Lu, J. Liu, B. Guo, P. Xiao, J.-J. Lee, X.-Q. Yang, G. Henkelman, J. B. Goodenough, J. Am. Chem. Soc. 2015, 137, 2658.

[12] M. B. Robin, Inorg. Chem. 1962, 1, 337.

[13] Y. Lu, J. B. Goodenough, Y. Kim, J. Am. Chem. Soc. 2011, 133, 5756. 


\section{WILEY-VCH}

[14] a) J. Qian, M. Zhou, Y. Cao, X. Ai, H. Yang, Adv. Energy Mater. 2012, 2, 410; b) Y.

You, X.-L. Wu, Y.-X. Yin, Y.-G. Guo, Energy Environ. Sci. 2014, 7, 1643; c) Y. You, X. Yu, Y. Yin, K.-W. Nam, Y.-G. Guo, Nano Res. 2015, 8, 117.

[15] a) H.-W. Lee, R. Y. Wang, M. Pasta, S. W. Lee, N. Liu, Y. Cui, Nat. Commun. 2014, 5, 5280; b) L. Wang, Y. Lu, J. Liu, M. Xu, J. Cheng, D. Zhang, J. B. Goodenough, Angew. Chem. Int. Ed. 2013, 52, 1964; c) T. Matsuda, M. Takachi, Y. Moritomo, Chem. Commun. 2013, 49, 2750.

[16] Y. Lu, L. Wang, J. Cheng, J. B. Goodenough, Chem. Commun. 2012, 48, 6544.

[17] a) C. D. Wessells, S. V. Peddada, R. A. Huggins, Y. Cui, Nano Lett. 2011, 11, 5421; b)

M. Pasta, C. D. Wessells, R. A. Huggins, Y. Cui, Nat. Commun. 2012, 3, 1149; c) X. Wu, Y. Luo, M. Sun, J. Qian, Y. Cao, X. Ai, H. Yang, Nano Energy 2015, 13, 117.

[18] A. Eftekhari, J. Power Sources 2004, 126, 221.

[19] L. Shen, Z. Wang, L. Chen, Chem. Euro. J. 2014, 20, 12559.

[20] a) T. Yamashita, P. Hayes, Appl. Surf. Sci. 2008, 254, 2441; b) L. Cao, Y. Liu, B.

Zhang, L. Lu, ACS Appl. Mater. Interfaces 2010, 2, 2339.

[21] M. Ware, J. Chem. Educ. 2008, 85, 612.

[22] D. Asakura, M. Okubo, Y. Mizuno, T. Kudo, H. Zhou, K. Ikedo, T. Mizokawa, A. Okazawa, N. Kojima, J. Phys. Chem. C 2012, 116, 8364.

[23] X. Wu, W. Deng, J. Qian, Y. Cao, X. Ai, H. Yang, J. Mater. Chem. A 2013, 1, 10130.

[24] S. M. Haight, D. T. Schwartz, M. A. Lilga, J. Electrochem. Soc. 1999, 146, 1866. 


\section{WILEY-VCH}
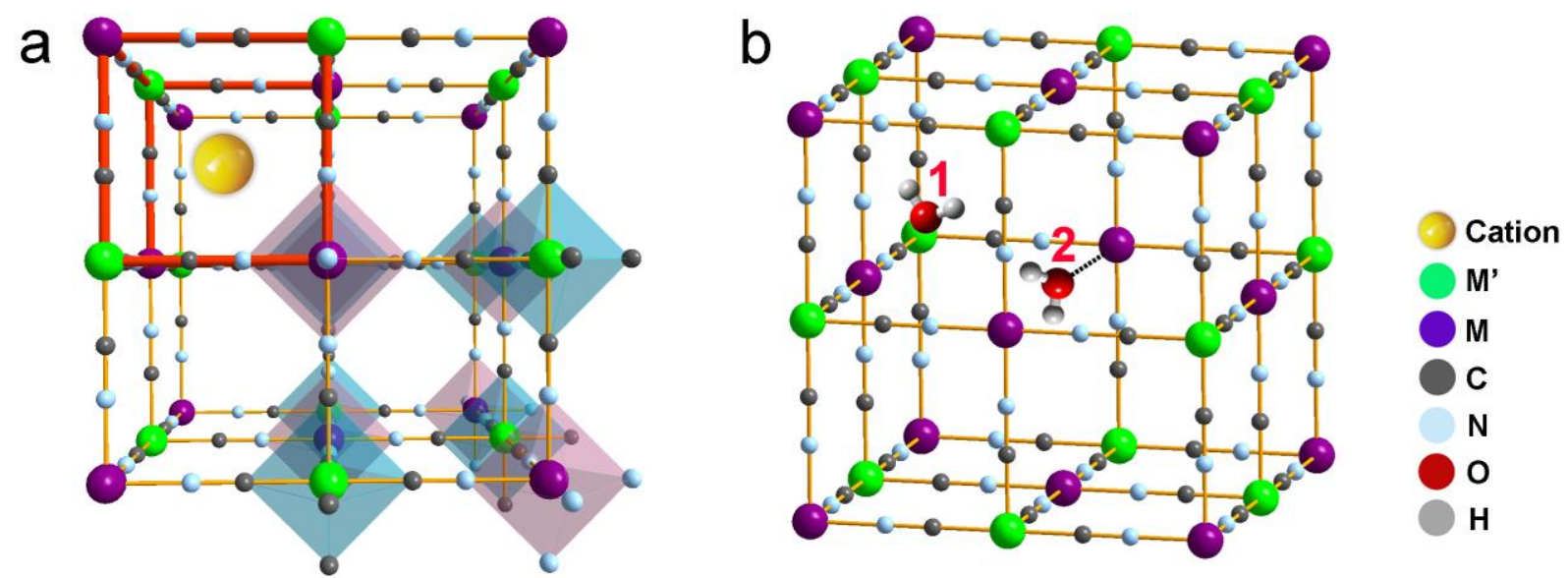

Figure 1. (a) Crystal structure of PBAs. (b) Positions of interstitial water. For simplicity, only one water molecule is shown for each kind.
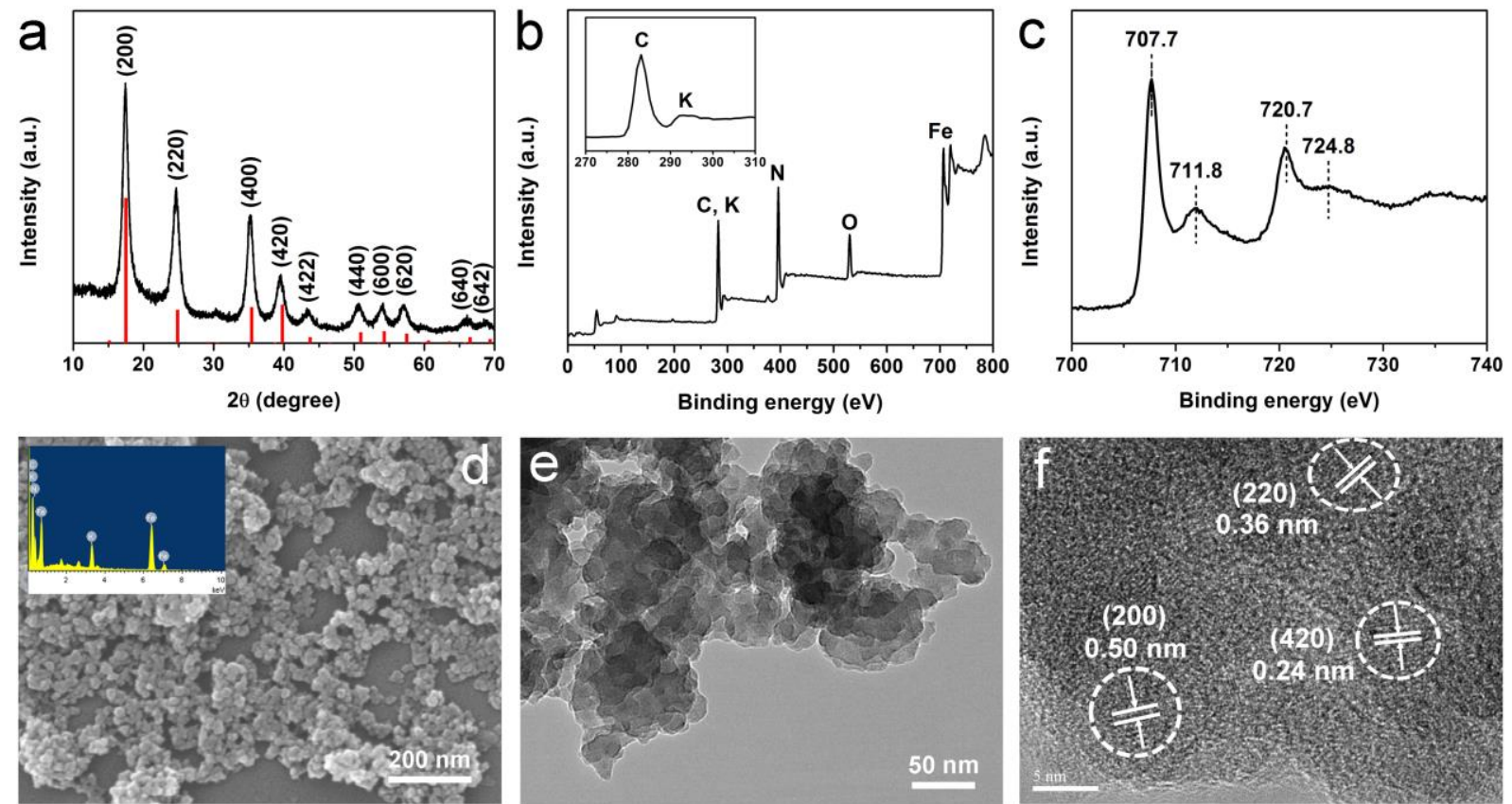

Figure 2. Structural characterizations of the KPBNPs: (a) XRD pattern; (b) XPS survey spectrum; (c) Fe 2p XPS spectrum; (d) SEM image (inset: EDS spectrum); (e) TEM image; (f) HRTEM image. 
WILEY-VCH
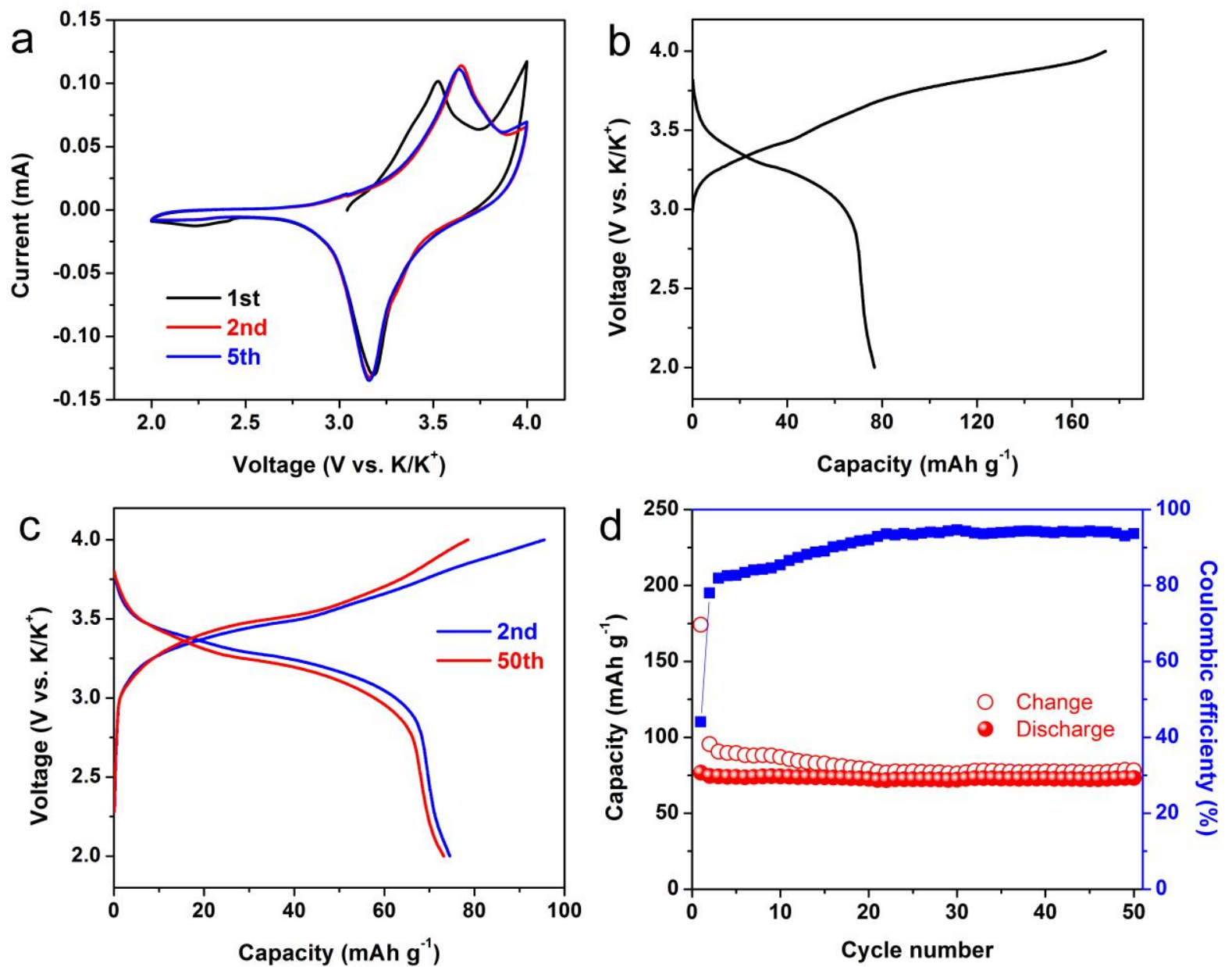

Figure 3. Electrochemical performance of the KPBNPs/K half-cell: (a) CV curves at a scan rate of $0.1 \mathrm{mV} \mathrm{s}^{-1}$; charge/discharge profiles of the 1st (b), 2nd and 50th cycles (c); (d) cycling performance at a current density of $50 \mathrm{~mA} \mathrm{~g}^{-1}$.
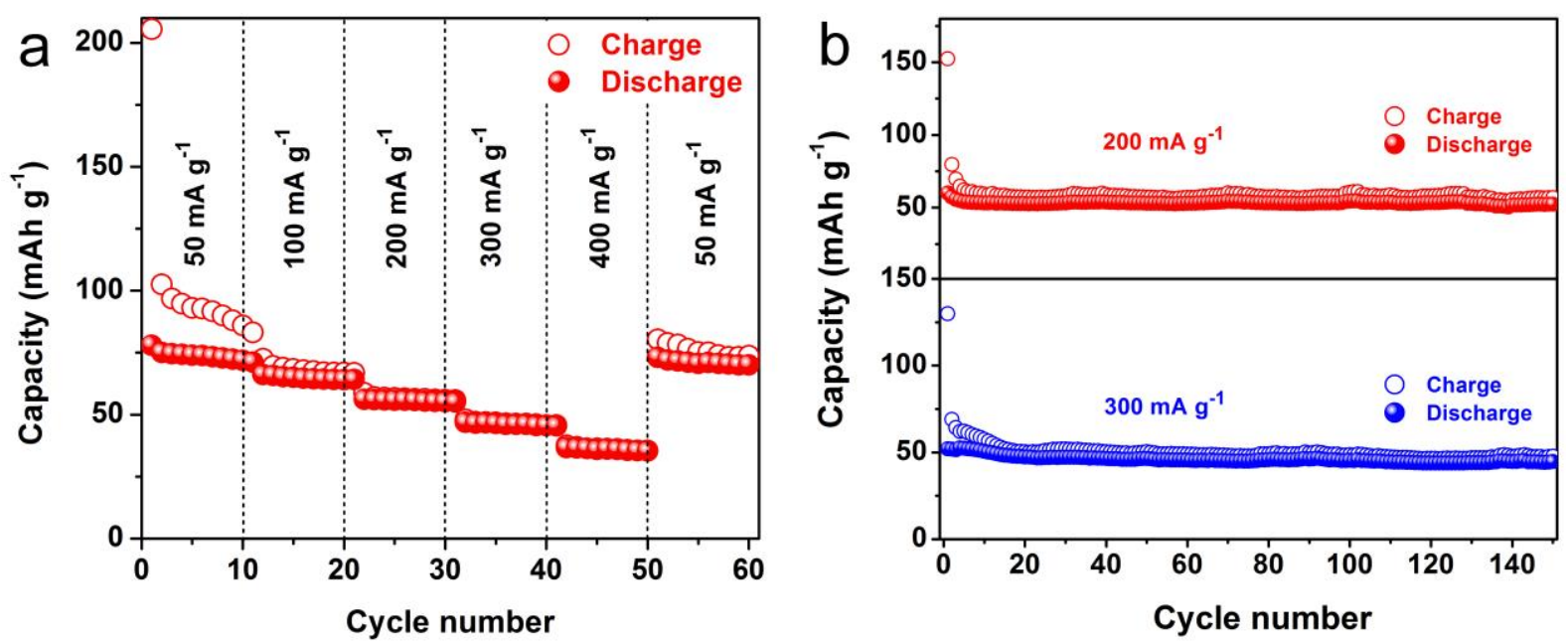

Figure 4. Rate (a) and cycling performances (b) of the KPBNPs/K half-cell at different rates. 
WILEY-VCH
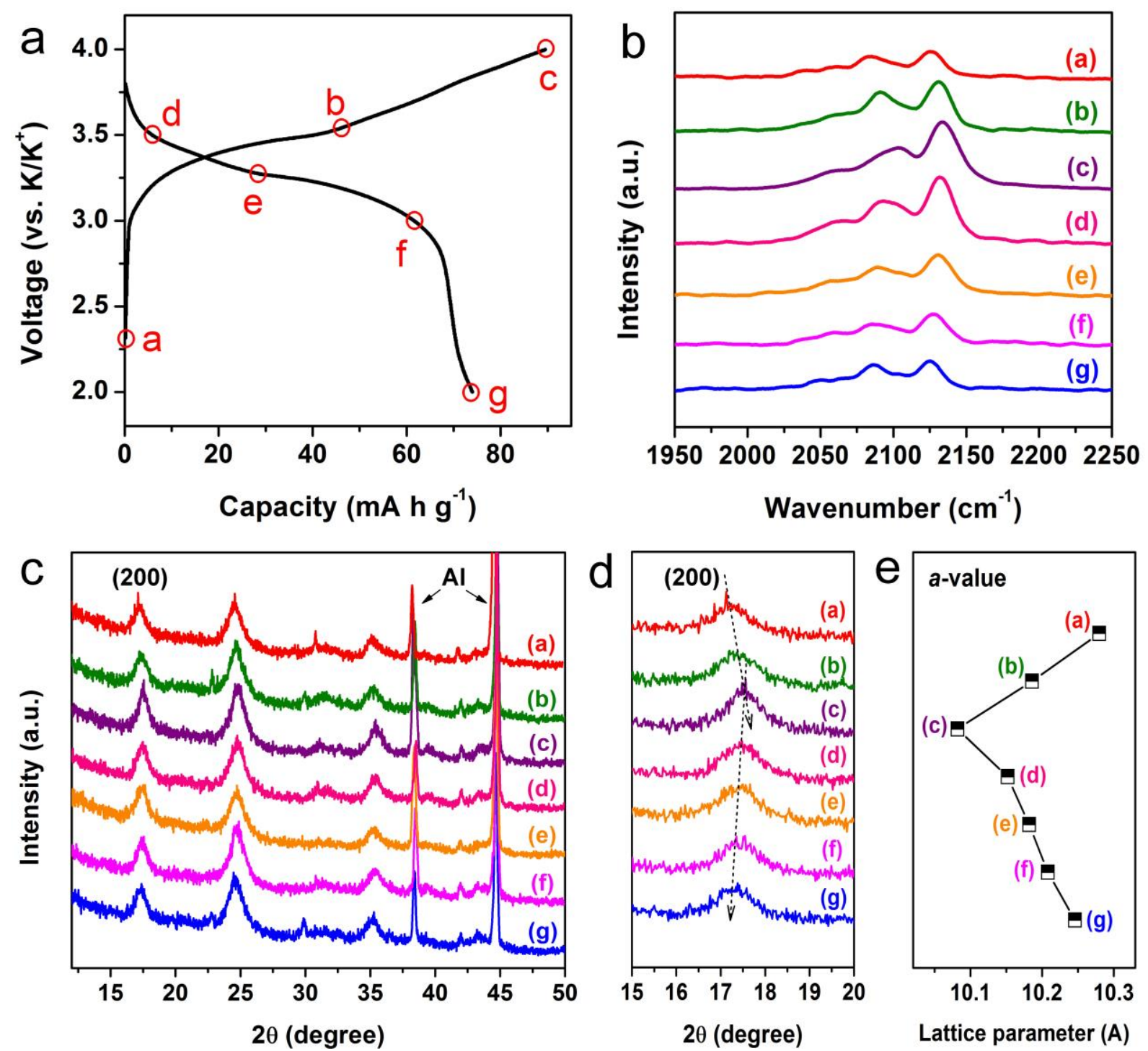

Figure 5. Electrochemical mechanism study of the KPBNPs: (a) indication of different charge and discharge states; (b) ex-situ Raman spectra at different states; (c) ex-situ XRD patterns at different states; (d) changes of the (200) diffraction peak; (e) changes of the lattice parameter calculated according to the (200) diffraction peak. 


\section{WILEY-VCH}
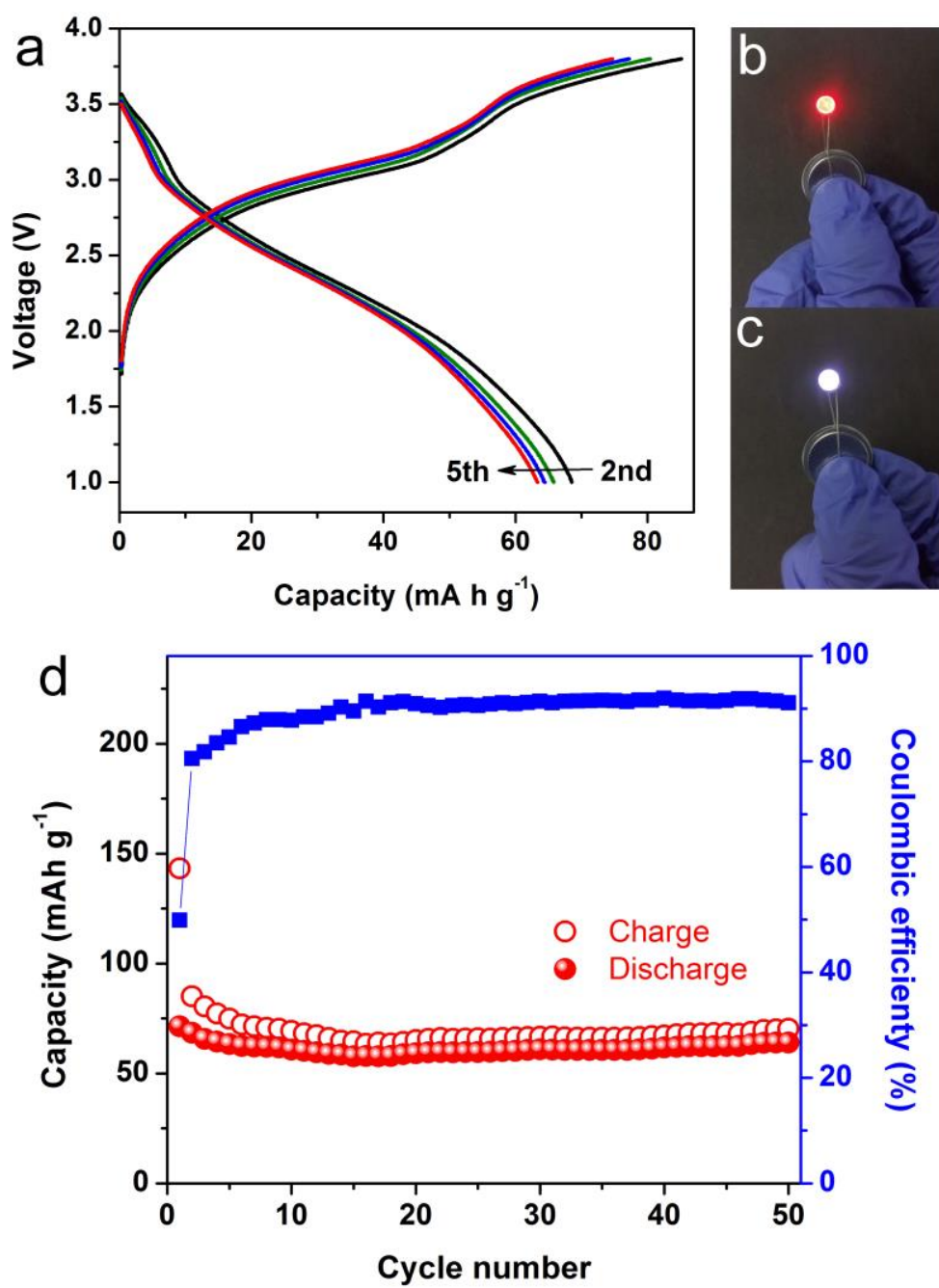

Figure 6. Electrochemical performance of the KPBNPs/Super P full-cell: (a) chargedischarge profiles at a current density of $100 \mathrm{~mA} \mathrm{~g}^{-1}$; optical photographs of a red LED (b) and white LED (c) lightened by the full-cell; (c) cycling performance at a current density of $100 \mathrm{~mA} \mathrm{~g}^{-1}$. 